\title{
THE ROLE OF EASE OF RETRIEVAL AND ATTRIBUTION IN MEMORY JUDGMENTS: Judging Your Memory as Worse Despite Recalling More Events
}

\author{
Piotr Winkielman, Norbert Schwarz, and Robert F. Belli \\ University of Michigan
}

\begin{abstract}
Participants who had to recall 12 childhood events (a difficult task) were more likely to infer that they could not remember large parts of their childhood than participants who had to recall 4 events (an easy task), although the former recalled three times as many events. This pattern of results suggests that memory judgments are based on the experienced ease or difficulty of recall. Accordingly, the negative impact of recalling 12 events was attenuated when participants were led to attribute the experienced difficulty to the task rather than to the poor quality of their memory. The findings emphasize the role of subjective experiences and attribution in metamemory judgments.
\end{abstract}

People's beliefs about memory have been assessed across a wide range of domains (see Dixon, 1989, and Herrmann, 1982, for reviews). The present research focuses on a topic that has received less research attention - the strategies that people use in assessing the quality of their memory. For example, suppose you are asked, "Are there large parts of your childhood after age 5 that you cannot remember?" and are offered the response alternatives "yes," "unsure," and "no" (Ross, 1989). How would you arrive at an answer? How do people evaluate their own memory for a specified time period? One possibility is that they focus on how much information they can retrieve about the specified time period. The more information is retrieved, the better their memory presumably is. An alternative possibility is based on the notion of the availability heuristic (Tversky \& Kahneman, 1973). When judging their memory, individuals may rely on the subjective experience of ease or difficulty of recall. If so, they may judge their memory as good when recall is experienced as easy, but as poor when recall is experienced as difficult.

Note, however, that the more events people attempt to recall, the more likely it is that they experience the task as difficult. Individuals who attempt to recall many events may not realize that the experienced difficulty is due to task demands and may instead attribute it to the poor quality of their memory. Hence, individuals who attempt to recall many events may infer poorer memory than individuals who attempt to recall only a few events, despite the fact that the former are likely to recall more material. The present research tested this paradoxical possibility, which is compatible with previous observations in other domains of judgment.

For example, Schwarz et al. (1991, Experiment 1) asked some participants to recall 6 examples of their own assertive behaviors (easy task) and others to recall 12 examples (difficult task). The latter participants subsequently evaluated themselves as less assertive than the former, despite the fact that they had just recalled twice as many assertive behaviors. Confirming the causal role of the phenomenal experi-

Address correspondence to Piotr Winkielman, Department of Psychology, Ohio State University, 1885 Neil Ave., Columbus, OH 43210-1222; e-mail: winkielman.1@osu.edu. ence of difficulty of recall, this finding was not obtained when participants were led to attribute the experienced difficulty to an irrelevant source, such as distracting music played to them (Schwarz et al., 1991, Experiment 3). In this case, individuals relied on the amount of recall and reported higher assertiveness after recalling 12 rather than 6 examples. As this example illustrates, recall tasks render two distinct sources of information accessible: the recalled content and the ease with which this content can be brought to mind. Depending on which of these sources individuals draw on, they may arrive at opposite conclusions (see Schwarz, in press, and Schwarz \& Clore, 1996, for a discussion of phenomenal experiences in judgment).

The present research extends previous work on the experience of remembering (for reviews, see Jacoby, Kelley, \& Dywan, 1989; Kelley \& Jacoby, 1996). This work has typically manipulated the ease of retrieval for specific items by some version of a priming procedure and addressed, for example, how retrieval fluency contributes to the subjective experience of remembering the item (e.g., Lindsay \& Kelley, 1996; Whittlesea, 1993) and to judgments of truth (e.g., Begg, Armour, \& Kerr, 1985) or confidence (e.g., Kelley \& Lindsay, 1993). Extending this work, the present study explores how the ease or difficulty with which material can be brought to mind in a free recall task influences more general metamemory judgments, such as "How good is my memory for my childhood?" Moreover, in the present study, we did not employ a priming procedure, but manipulated recall difficulty by asking participants to recall either a few or many memories from a specified time period, thus pitching the implications of the amount of recall against the implications of the subjective experience of ease or difficulty of recall.

Specifically, participants were asked to recall either 4 or 12 childhood events. Whereas the former task is experienced as easy, the latter is experienced as difficult. Subsequently, they rated the completeness of their childhood memory. We predicted that participants would rate their memory as worse after successfully retrieving many childhood events than after retrieving a few childhood events, in contrast to what the actual number of recalled events would seem to imply.

If obtained, this finding would indicate that participants misattribute the difficulty of the task to the poor quality of their memory. To provide a direct test of this interpretation, we informed some of the participants who had to recall 12 events that most people find this task rather difficult. We predicted that these participants would rate their childhood memory as more complete than participants who completed the same recall task without information about the task's difficulty. Conversely, we tried to inhibit task attributions by informing other participants that most people find it easy to recall 12 events. We expected these participants to be particularly likely to rate their childhood memory as incomplete. Such a differential impact of the same recall experience would further support the informative role of recall experiences in memory judgments by demonstrating that the impact of these experiences depends on their perceived diagnosticity (see Schwarz \& Clore, 1996, for a review of related findings in other domains). 
Finally, we included a condition in which participants rated the completeness of their childhood memory before they retrieved 12 childhood events. The judgments obtained in this condition presumably reflected participants' default assumptions about their memory, thus providing a baseline against which the impact of recalling 4 versus 12 events could be assessed.

Following their memory judgments, participants asked to recall 4 events were asked to recall an additional 8 events. This procedure allowed us to ensure that all participants could recall 12 events and that any differences in their memory judgments did not reflect differences in the amount of information that could be retrieved.

\section{METHODS}

\section{Participants}

The participants were 142 undergraduates at the University of Michigan (61\% women, $39 \%$ men; mean age $=19.9$ years).

\section{Materials and Procedure}

In various settings (before a lecture, in a library), participants were randomly given one of five versions of a "memory questionnaire." In the 0 -events condition, participants were first asked about the completeness of their childhood memory: "Regarding childhood memory, are there large parts of your childhood after age 5 which you can't remember?" Response options were "yes," "no," and "unsure" (modeled after Ross, 1989). Next, participants were asked to report 12 events that they experienced while they were 5 to 7 years old and 8 to 10 years old. They had to report 6 specific events on six numbered lines for each age period. Finally, participants rated their recall experience: "Now we want you to think back to the task where you had to write down several different childhood events. How difficult was this task for you?" They responded on a scale ranging from 1 (very easy) to 7 (very difficult).

In the 4-events condition, participants were first asked to report 4 childhood events ( 2 for each age period). Next, they were asked about the completeness of their childhood memory and the difficulty of their recall experience. Finally, the participants were asked to report an additional 8 events.

There were three 12-events versions of the questionnaire. In each version, participants were asked to report 12 childhood events ( 6 for each age period). Before the recall task, participants assigned to the 12-events/difficult condition were informed that "most people find recalling childhood events difficult." Participants assigned to the 12events/easy condition were informed that "most people find recalling childhood events easy." Participants assigned to the 12-events/control condition received no information about task difficulty. After the recall task, participants were asked about the completeness of their childhood memory and the difficulty of their recall experience.

\section{RESULTS}

\section{Manipulation Checks}

Our manipulation of recall difficulty was successful. Participants who had to recall 12 events and received no information about task difficulty rated the recall task as more difficult $(M=3.98)$ than participants who had to recall only 4 events initially $(M=3.00), t(46)=2.24$, $p<.05$. As expected, the compliance with experimental instructions was very good, with $91.5 \%$ of the participants retrieving all requested events. To ensure that our analyses were based on responses of participants who did not experience any failures to retrieve requested events, we excluded from further analyses the $8.5 \%$ (12) participants who did not report all 12 events. However, the results of all critical tests are similar when all participants are left in the sample.

\section{Judgments of Childhood Memory}

Table 1 shows participants' responses to the memory question. The reports of poor childhood memory increased with the number of events recalled: Whereas only $19 \%$ of the participants who had to recall 4 events reported that they could not remember large parts of their childhood, $46 \%$ of the participants who had to recall 12 events (and received no information about task difficulty) did so. The judgments of participants who answered the memory question before they retrieved childhood events ( 0 -events condition) fell in between these extremes (37\% "yes" responses).

The proportions of "yes" responses in the 4-events and 12-events/ control conditions were compared using contrast analysis on proportions (Rosenthal \& Rosnow, 1985). The analyses were set up in two ways. One analysis compared "yes" responses with "unsure" and "no" responses combined $(z=2.05, p=.04)$. The other analysis compared only "yes" and "no" responses $(z=2.43, p=.02)$.

To assess the relative contribution of experienced ease and difficulty, we constructed a logistic regression model that treated the responses to the memory question as an ordinal level dependent variable ("yes" $=-1$, "unsure" $=0$, "no" = 1 ), using the 0 -events condition as the referent group. Results confirmed the prediction that participants in the 0 -events condition would provide significantly more "yes" responses and significantly fewer "no" responses than those in the 4events condition $(\beta=-0.85, p=.05)$. Moreover, they also provided significantly fewer "yes" responses and significantly more "no" responses than those in the 12-events/control condition $(\beta=0.78, p<.05)$. These findings indicate that experienced ease of recall leads to judgments of better childhood memory, whereas experienced difficulty of recall leads to judgments of poorer childhood memory, relative to a condition in which no experiential information is available.

We further hypothesized that the impact of a given recall experience depends on its perceived diagnosticity for the judgment at hand.

Table 1. Number and percentage of participants endorsing each response category when asked, "Regarding childhood memory, are there large parts of your childhood after age 5 which you can't remember?"

\begin{tabular}{lrrr}
\hline \hline \multirow{2}{*}{ Condition } & \multicolumn{3}{c}{ Response category } \\
\cline { 2 - 4 } \multicolumn{1}{c}{ Yes } & Unsure & No \\
\hline 0 events & $11(37 \%)$ & $7(23 \%)$ & $12(40 \%)$ \\
4 events & $4(19 \%)$ & $6(29 \%)$ & $11(52 \%)$ \\
12 events/control & $13(46 \%)$ & $8(29 \%)$ & $7(25 \%)$ \\
12 events/difficult & $7(27 \%)$ & $5(19 \%)$ & $14(54 \%)$ \\
12 events/easy & $11(44 \%)$ & $5(20 \%)$ & $9(36 \%)$ \\
& & &
\end{tabular}


Accordingly, we predicted that participants who attributed the difficulty they encountered in recalling 12 events to the nature of the task would not use this difficulty as diagnostic information in assessing the completeness of their childhood memory. The pattern of results confirmed this prediction. Without information about task difficulty, $46 \%$ of the participants who had to recall 12 events responded with "yes" when asked if their childhood memory was incomplete. In contrast, this was true for only $27 \%$ of the participants who were informed that most people find the task difficult. Again, two contrast analyses on proportions were performed. One analysis compared "yes" responses with "unsure" and "no" responses combined $(z=1.52, p<.12)$. The other analysis compared only "yes" and "no" responses $(z=2.13, p<.04)$. Moreover, when participants were informed about the task difficulty, their memory judgments did not differ from the judgments provided by participants who had to recall either 4 events or no event at all ( $p \mathrm{~s}>.30$, irrespective of response combination).

Finally, we predicted that informing participants that most people find the task easy would enhance the impact of the difficulty they experienced in recalling 12 events. Contrary to this prediction, however, the responses obtained in this condition did not differ from the responses provided by participants who received no information about task difficulty ( $p>.3$, for both response combinations). Informing participants that other people find the task easy may not have added much to the interpretation of their phenomenal experience. In fact, most people are likely to expect that they can retrieve a dozen childhood events without much difficulty, thus rendering the task information redundant. Hence, participants in the 12-events/easy condition and the 12events/control condition may have found the experienced difficulty equally surprising and diagnostic.

\section{DISCUSSION}

Our results suggest that one's judgments of memory are influenced by the number of events one is asked to retrieve. Paradoxically, asking people to recall more events results in lower estimates of memory completeness, contrary to what would be expected if people based their judgments on the number of recalled events. We suggest that this effect reflects the fact that a recall task makes accessible two distinct sources of information: the recalled content and the ease with which this content comes to mind. Depending on which of these sources individuals draw on, they may arrive at opposite conclusions (Schwarz et al., 1991; Wänke, Schwarz, \& Bless, 1995). Recalling many events is generally experienced as more difficult than recalling a few events. If people focus on the experienced difficulty, and do not take the task demands sufficiently into account, they may misattribute the experienced difficulty to the poor quality of their memory. Consistent with this interpretation, the impact of recall difficulty was attenuated when participants were led to attribute it to the nature of the task.

These results are consistent with related research that highlighted the role of phenomenal experiences in memory judgments (see Jacoby et al., 1989; Kelley \& Jacoby, 1996, for reviews). This research focused on the ease or difficulty with which a specific item comes to mind. Extending this work, the present findings demonstrate that recall experiences not only may influence judgments pertaining to specific items, but also may influence assessments of the quality of one's memory in general. Moreover, the present manipulations illustrate that the sheer attempt to recall a large amount of material may result in inferences of poor memory, even when the recall attempt is successful, as was the case in the present study.
At a general level, our findings contribute to the research on the judgmental processes that underlie respondents' answers to questions about their memories (see Dixon, 1989, and Herrmann, 1982, for reviews). They draw attention to the questions that have gone largely unnoticed in this literature: What are the strategies that people use in assessing the quality of their memory? Do they rely on the number of events that can be retrieved or on the subjective experience accompanying the recall? What is the role of attribution in this process? Our findings also have important implications for clinicians and researchers interested in the validity of self-reported amnesia for childhood events following memory work (Belli \& Loftus, 1994; Belli, Winkielman, Read, Schwarz, \& Lynn, in press; Ceci \& Loftus, 1994; Lindsay \& Read, 1994). Our findings highlight that reports of poor childhood memory may simply reflect the fact that recalling childhood events is more difficult than people think-leading them to infer poorer memory the more events they (successfully) try to recall.

Acknowledgments—The authors would like to thank Kent Harber, Tim Ketelaar, Barbel Knauper, Magdalena Ponurska, Don Read, Uli Schimmack, Bob Wyer, and two anonymous reviewers for their help with this article.

\section{REFERENCES}

Begg, I., Armour, V., \& Kerr, T. (1985). On believing what we remember. Canadian Journal of Behavioral Science, 17, 199-214.

Belli, R.F., \& Loftus, E.F. (1994). Recovered memories of childhood abuse: A source monitoring perspective. In S.J. Lynn \& J. Rhue (Eds.), Dissociation: Theory, clinical, and research perspectives (pp. 415-433). New York: Guilford Press.

Belli, R.F., Winkielman, P., Read, J.D., Schwarz, N., \& Lynn, S.J. (in press). Recalling more childhood events leads to judgments of poorer memory: Implications for the recovered/false memory debate. Psychonomic Bulletin \& Review.

Ceci, S.J., \& Loftus, E.F. (1994). 'Memory work': A royal road to false memories? Applied Cognitive Psychology, 8, 351-364.

Dixon, R.A. (1989). Questionnaire research on metamemory and aging. In L.W. Poon, D.C. Rubin, \& B.A. Wilson (Eds.), Everyday cognition in adulthood and late life (pp. 394-415). New York: Cambridge University Press.

Herrmann, D.J. (1982). Know thy memory: The use of questionnaires to assess and study memory. Psychological Bulletin, 92, 434-452.

Jacoby, L.L., Kelley, C.M., \& Dywan, J. (1989). Memory attributions. In H.L. Roediger, III, \& F.I.M. Craik (Eds.), Varieties of memory and consciousness: Essays in honor of Endel Tulving (pp. 391-422). Hillsdale, NJ: Erlbaum.

Kelley, C.M., \& Jacoby, L.L. (1996). Memory attributions: Remembering, knowing, and feeling of knowing. In L.M. Reder (Ed.), Implicit memory and metacognition (pp. 287-308). Mahwah, NJ: Erlbaum.

Kelley, C.M., \& Lindsay, D.S. (1993). Remembering mistaken for knowing: Ease of retrieval as a basis for confidence in answers to general knowledge questions. Journal of Memory and Language, 32, 1-24.

Lindsay, D.S., \& Kelley, C.M. (1996). Creating illusions of familiarity in a cued recall remember/know paradigm. Journal of Memory and Language, 35, 197-211.

Lindsay, D.S., \& Read, J.D. (1994). Psychotherapy and memories of childhood sexual abuse: A cognitive perspective. Applied Cognitive Psychology, 8, 281-338.

Rosenthal, R., \& Rosnow, R.L. (1985). Contrast analysis: Focused comparisons in the analysis of variance. Cambridge, England: Cambridge University Press.

Ross, C.A. (1989). Multiple personality disorder: Diagnosis, clinical features, and treatment. New York: Wiley.

Schwarz, N. (in press). Accessible content and accessibility experiences: The interplay of declarative and experiential information in judgment. In J. Metcalfe \& F. Strack (Eds.), Metacognition [Special issue]. Personality and Social Psychology Review.

Schwarz, N., Bless, H., Strack, F., Klumpp, G., Rittenauer-Schatka, H., \& Simons, A. (1991). Ease of retrieval as information: Another look at the availability heuristic. Journal of Personality and Social Psychology, 61, 195-202.

Schwarz, N., \& Clore, G.L. (1996). Feelings and phenomenal experiences. In E.T. Higgins \& A. Kruglanski (Eds.), Social psychology: A handbook of basic principles (pp. 433-465). New York: Guilford Press.

Tversky, A., \& Kahneman, D. (1973). Availability: A heuristic for judging frequency and probability. Cognitive Psychology, 5, 207-232.

Wänke, M., Schwarz, N., \& Bless, H. (1995). The availability heuristic revisited: Experienced ease of retrieval in mundane frequency estimates. Acta Psychologica, 89, 83-90.

Whittlesea, B.W.A. (1993). Illusions of familiarity. Journal of Experimental Psychology: Learning, Memory, and Cognition, 19, 1235-1253.

(RECEIVED 10/30/96; REVISION ACCEPTED 10/3/97) 